\title{
BANCO DE SEMENTES DO SOLO, COMO SUBSÍDIO À RECOMPOSIÇÃO DE MATA CILIAR
}

\author{
Israel Marinho Pereira ${ }^{1}$, Auwdréia Pereira Alvarenga ${ }^{2}$, Soraya Alvarenga Botelho ${ }^{3}$ \\ ${ }^{1}$ Eng. Florestal, Dr., Depto. de Engenharia Florestal, UFVJM, Diamantina, Minas Gerais, Brasil - imarinhopereira@gmail.com \\ ${ }^{2}$ Eng $^{\mathrm{a}}$ Florestal, M.Sc., UFVJM, Diamantina, Minas Gerais, Brasil - auwdreia@gmail.com \\ ${ }^{3}$ Eng $^{\mathrm{a}}$ Florestal, Dr ${ }^{\mathrm{a}}$., Depto. de Engenharia Florestal, UFLA, Lavras, Minas Gerais, Brasil - sbotelho@ufla.br \\ Recebido para publicação: 10/09/2008 - Aceito para publicação: 14/08/2010
}

\begin{abstract}
Resumo
O presente trabalho teve como objetivo conhecer a densidade e composição do banco de sementes do solo em dois ambientes de mata ciliar alterada, no entorno de uma nascente. A nascente estudada pertence à bacia hidrográfica do rio Capivari, no município de Itumirim, MG (21 ${ }^{\circ} 16^{\prime} \mathrm{S}$ e $44^{\circ} 52^{\prime}$ W $)$. Nos dois ambientes estudados, foram coletadas 18 amostras de solo a 5,0 cm profundidade, no final da estação chuvosa (maio de 2003). Calculou-se a densidade de sementes e a curva de germinação do banco pelo método de emergência de plântulas. Também foi feita a determinação da composição florística, com base principalmente na morfologia das plântulas. Após um período de 210 dias de avaliação, obteve-se uma densidade de 2.332 sementes $/ \mathrm{m}^{2}$ no Ambiente I e 1.896 sementes $/ \mathrm{m}^{2}$ no Ambiente II. No entanto constatou-se que o banco de sementes dos dois ambientes avaliados era composto apenas por espécies ruderais. Tais resultados evidenciam a necessidade de intervenção humana no processo de recomposição da vegetação ciliar no entorno dessa nascente, por meio da regeneração artificial de espécies arbóreas.

Palavras-chave: Banco de sementes do solo; nascente e recomposição da vegetação.
\end{abstract}

\begin{abstract}
Soil seed bank as to grant recovery of the riparian forest. The present work objective knows the density and composition of soil seed bank in ciliary areas altered in spill of two springs. The studied springs belong to Capivari river catchment, Itumirim, MG $\left(21^{\circ} 16^{\prime} \mathrm{S}\right.$ and $\left.44^{\circ} 52^{\prime} \mathrm{W}\right)$. The samples of soils were collected in the end of the rainy station (May of 2003). Were 18 soil samples were collected for the two environments to the depth of $5 \mathrm{~cm}$. was calculated the density of seeds and the curve of germination of the soil seed bank, for method of seedling emergency. It was also made the determination of the floristic composition based mainly on the morphology of the seedling. After a period of 210 days of evaluation obtained a density of $2332 \mathrm{seed} / \mathrm{m}^{2}$ was observed in the environment I and $1896 \mathrm{seed} / \mathrm{m}^{2}$, for the environment. However, it was verified that the bank of seeds of the two appraised East was just composed of ruderal species. Such results evidence the need of human intervention in the process of restoration of the ciliary vegetation in spill of this spring, through the artificial regeneration of the arboreal species.

Keyword: Seed bank; spring and restoration of the vegetation.
\end{abstract}

\section{INTRODUÇÃO}

A recomposição de ecossistemas degradados envolve conhecimentos diversos, principalmente no que se refere à funcionalidade e à dinâmica das espécies, essenciais à formação estrutural das comunidades. O conhecimento da dinâmica natural e da estrutura do ecossistema é fundamental no desenvolvimento de modelos de recuperação (ARAÚJO et al., 2001). O processo de sucessão ecológica em áreas que sofreram intervenção antrópica, tais como campos agrícolas e pastagens abandonadas e áreas de mineração com pouca alteração na estrutura do solo, desencadeia-se pela germinação de sementes recém-dispersas até o sítio e pelas sementes dormentes contidas no banco de sementes do solo.

A expressão banco de semente do solo foi utilizado por Roberts (1981) para designar o reservatório viável de sementes atual em uma determinada área de solo. Para Grime (1989), o banco de 
sementes é uma agregação de sementes não-germinadas, potencialmente capazes de substituir plantas adultas anuais, que podem morrer de forma natural ou não-natural, e plantas perenes susceptíveis de morte por doenças, perturbação ou consumo por animais.

De acordo com Kageyama; Viana (1991), o banco de sementes do solo é caracterizado pela quantidade de sementes existentes no solo, num dado momento e numa dada área. De acordo com Leal Filho (1992), o conhecimento de seu tamanho, de sua composição florística, assim como de sua dinâmica, é fator importante na compreensão dos mecanismos que controlam a sucessão vegetal nos trópicos.

A fonte de sementes do banco é a chuva de sementes proveniente da comunidade local, da vizinhança e de áreas distantes, quando as sementes são dispersas após os distintos processos de dispersão (anemocoria, endozoocoria, epizoocoria, hidrocoria e autocoria) (HALL; SWAINE, 1980).

$\mathrm{O}$ banco de sementes em florestas tropicais está relacionado a pelo menos quatro processos nos níveis de população e de comunidade: o estabelecimento de populações, a manutenção da biodiversidade de espécies, o estabelecimento de grupos ecológicos e a restauração da riqueza de espécies durante a regeneração natural da floresta após distúrbios naturais ou antrópicos (HARPER, 1977; UHL et al., 1988). O banco de sementes do solo pode servir também como uma fonte importante de propágulos para recolonização de uma área após distúrbio (TEKLE; BEKELE, 2000).

Vários estudos sugerem que a densidade e diversidade de sementes armazenadas no solo possam fornecer indicações sobre a resiliência de uma determinada área, uma vez que a germinação das sementes presentes no banco é uma das fontes de entrada dos indivíduos na comunidade (ONAINDIA; AMEZAGA, 2000).

O banco de sementes, em determinada área, apresenta variações espaciais tanto no sentido horizontal como no vertical, ou seja, ele varia entre locais dentro da mesma área e também se modifica em relação à profundidade do solo. Quanto à distribuição das sementes no perfil do solo, os trabalhos evidenciam que ocorre uma queda acentuada na quantidade de sementes com o aumento da profundidade, sendo que a maior parte das sementes se encontra nos $5 \mathrm{~cm}$ superficiais (HARPER, 1977; ROIZMAN, 1993; BAIDER et al., 1999; MARTINS, 2001).

Têm-se constatado que o banco de sementes das florestas tropicais é composto, basicamente, por espécies pioneiras herbáceas e arbustivo-arbóreas de ciclo de vida curto (PUTZ; APPANAH, 1987; BAIDER et al., 1999; SOUZA, 2002). Espécies herbáceas pioneiras não são componentes típicos das florestas tropicais, porém vem sendo registradas em grande número nos estudos de banco de sementes, pois geralmente apresentam dormência facultativa, além de disporem de mecanismos de dispersão eficientes (HOPKINS; GRAHAM, 1984; WHITMORE, 1990; BAIDER et al., 1999).

O estoque de sementes no solo é formado por espécies representativas da vegetação atual, espécies de etapas sucessionais anteriores e espécies que nunca estiveram presentes na área, mas que formam parte do banco (SORREANO, 2002).

O banco de sementes pode ser visto como um processo dinâmico, que tem entradas e saídas. O balanço entre entradas de novas sementes e saídas, por germinação, deterioração, parasitismo, predação e transporte por vários agentes, determina um estoque acumulado, que varia substancialmente em função do tipo de sementes, caracterizando bancos transitórios, ou seja, aqueles constituídos de sementes que germinam logo após a dispersão ou no período de no máximo um ano, e bancos persistentes, aqueles compostos por sementes viáveis durante um período de tempo suficientemente longo, para que novas produções possam repor eventuais perdas ocorridas (SIMPSON et al., 1989).

De acordo com Martins et al. (2009), as espécies pioneiras intolerantes à sombra compõem o banco de sementes persistente, sendo o principal grupo de plantas responsável pela cicatrização de grandes clareiras nas florestas tropicais. A habilidade dessas espécies em permanecer dormentes no banco é uma importante estratégia biológica para a dinâmica de suas populações, permitindo que acompanhem a abertura de clareiras na floresta ou mudanças drásticas em comunidades. Desse modo, quando ocorre abertura de clareiras, a colonização das mesmas é dada pela ativação do banco de sementes, associado com a chuva de sementes que cai sobre tais áreas (RICHARDS, 1998).

O período de tempo em que as sementes permanecem no banco é determinado por fatores fisiológicos (germinação, dormência e viabilidade) e ambientais (umidade, temperatura, luz, presença de predadores de sementes e patógenos) (GARWOOD, 1989).

A grande maioria dos estudos desenvolvidos, tanto nas regiões tropicais quanto nas temperadas, destaca que o banco de sementes se compõe, principalmente, de sementes de espécies pioneiras de 
gramíneas, cipós, arbustos e árvores, ou seja, aquelas espécies características dos estágios iniciais da sucessão, cujas plântulas e arvoretas não sobrevivem fora de áreas abertas (SMITH, 1987; SAULEI; SWAINE, 1988; GARWOOD, 1989; BAIDER et al., 1999). A dormência e longevidade da maioria das sementes das espécies pioneiras são as causas da sua capacidade de formar estoques no banco de sementes.

Diversos estudos têm sido realizados com o objetivo de melhor conhecer os processos naturais de recuperação em pastagens, áreas cultivadas para agricultura e florestas alteradas (UHL et al., 1988; VIANA, 1990; WIESENMULLER, 1995; NEPSTAD et al., 1998). O tipo e a intensidade do distúrbio dependem da natureza do processo de uso da terra que ocorre nas diferentes regiões alteradas, apresentando influência no padrão de recuperação natural do ecossistema (ARAÚJO et al., 2001).

A regeneração artificial em áreas perturbadas pode ser melhor planejada se, efetivamente, forem levantadas informações sobre o estado do banco de sementes das mesmas (TEKLE; BEKELE, 2000). Garwood (1989) também salienta que a riqueza e abundância de espécies no banco de sementes (associado com a chuva de sementes) contribuem com importantes informações sobre o potencial de regeneração das comunidades.

A hipótese testada é de que ocorram resultados diferenciados em termos de germinação, riqueza, composição e potencial do banco para recuperação das áreas, sendo maior na nascente perturbada e menor na degradada.

Nesse sentido, o presente trabalho teve como objetivo conhecer a composição do banco de semente do solo e avaliar seu potencial no estabelecimento inicial da vegetação no entorno de uma nascente.

\section{MATERIAL E MÉTODOS}

\section{Área de estudo}

$\mathrm{O}$ estudo foi realizado no entorno de uma nascente no município de Itumirim, MG, situada na bacia do rio Capivari, afluente do rio Grande, margem direita ( $21^{\circ} 16^{\prime}$ ' S e $44^{\circ} 52^{\prime}$ W), a 892 metros de altitude (Figura 1). Por apresentar situações distintas, essa nascente foi dividida em dois ambientes, assim caracterizados: Ambiente I (perturbado): ambiente da nascente que não possui a faixa mínima de 50 metros de vegetação no seu entorno, mas apresenta bom estado de conservação, apesar de estar em parte ocupada por pastagem; e Ambiente II (degradado): ambiente que apresenta pouca ou nenhuma vegetação, com presença de gado e erosão e ocupado também com pastagem.

O clima da região é do tipo Cwa, de acordo com a classificação de Köppen. A temperatura média anual encontra-se entorno de $19,3^{\circ} \mathrm{C}$. A temperatura média do mês mais frio e do mês mais quente são $15,8^{\circ}$ e $22,1^{\circ} \mathrm{C}$, respectivamente. A precipitação média anual é de $1.530 \mathrm{~mm}$, e a umidade relativa média anual é de $76 \%$ (BRASIL, 1992).
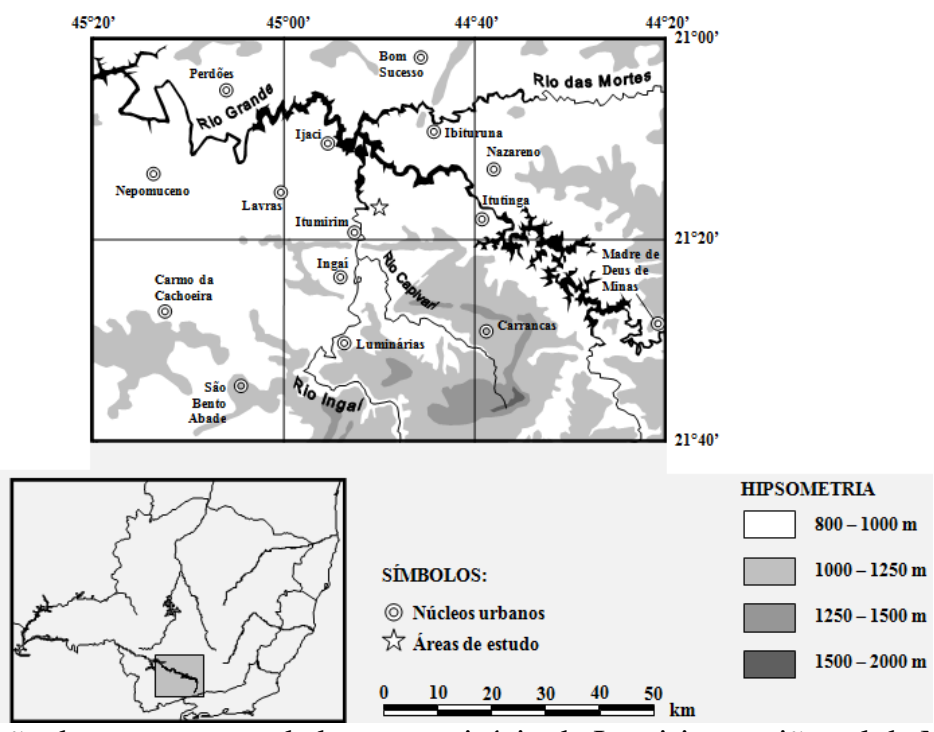

Figura 1. Localização da nascente estudada, no município de Itumirim, região sul de Minas Gerais, MG. Figure 1. Location of the spring studied in the southern region of Minas Gerais, Brazil. 


\section{Amostragem e processamento dos dados}

A avaliação do banco de sementes do solo foi realizada por meio do método indireto, ou seja, pela identificação e quantificação das plântulas germinadas nas amostras. As coletas de solo para a realização do presente estudo foram realizadas no mês de maio de 2003. As amostras foram coletadas sistematicamente a cada $20 \mathrm{~m}$, até a profundidade de $5,0 \mathrm{~cm}$. Foram coletadas, no total, 18 amostras, sendo nove amostras no ambiente perturbado e nove no ambiente degradado.

O material foi coletado com auxílio de um gabarito de madeira com dimensões de 21,5 x 21,5 e $5,0 \mathrm{~cm}$ de profundidade, resultando em um volume total de solo coletado de $0,0023 \mathrm{~m}^{3}$ e em uma área de $0,0462 \mathrm{~m}^{2}$. As amostras foram acondicionadas em sacos plásticos pretos e levadas para o Viveiro Florestal do DCF/UFLA, onde foram passadas por peneira grossa, para retirada de tocos, raízes e para destorroamento, sendo posteriormente homogeneizadas. De cada amostra foram retirados 1,2 litros de solo $(1 \mathrm{~cm})$, que foi colocado em bandejas plásticas de $44,2 \mathrm{~cm} \times 28 \mathrm{~cm} \times 7,5 \mathrm{~cm}$, contendo $2 \mathrm{~cm}$ de areia esterilizada a $120{ }^{\circ} \mathrm{C}$ durante 1 hora. As bandejas foram acondicionadas em casa de vegetação, onde foram regadas diariamente.

O experimento foi conduzido em casa de vegetação por um período de 210 dias. As plântulas emergentes foram contadas, semanalmente, durante os primeiros 60 dias e, após esse período, de 15 em 15 dias, sendo que as plântulas de gramíneas (Poaceae) eram retiradas imediatamente após seu registro e identificação.

As espécies foram classificadas nas famílias reconhecidas pelo sistema do Angiosperm Phylogeny Group II (APG 2003).

Foram calculados, para cada ambiente, o índice de diversidade de Shannon $\left(H^{\prime}\right)$ e a equabilidade de Pielou $\left(J^{\prime}\right)$ (KREBS, 1989), em base logarítmica natural (BROWER; ZAR, 1984). Os índices de diversidade de Shannon, entre os dois ambientes, foram comparados pelo teste de $t$ de Hutcheson (ZAR, 1996). Já os dados referentes ao número de indivíduos e densidade de sementes foram submetidos a análise de variância, realizadas no programa SISVAR, e as médias comparadas entre si pelo teste de Scott-Knott, a 5\% de probabilidade.

\section{RESULTADOS E DISCUSSÃO}

Verifica-se, na tabela 1, que o banco de sementes do solo total dos dois ambientes avaliados foi composto por 731 plântulas, sendo 380 no ambiente I e 351 no Ambiente II. No total, foi registrada a ocorrência de dez espécies, pertencentes a dez gêneros e seis famílias botânicas, sendo $60 \%$ delas registradas no Ambiente I. Do total de plântulas emergidas no Ambiente I, 132 (34,74\%) pertencem à família Poaceae (graminoides), 197 (51,8\%) à família Malvaceae e 51 (13,4\%) a outras quatro famílias. Já no Ambiente II, aproximadamente $74 \%$ das plântulas pertencem à família Poaceae, $25 \%$ à família Malvaceae e apenas 1\% a outras famílias botânicas (Tabela 1). Leal Filho (1992), estudando o banco de sementes de três estágios sucessionais na Zona da Mata, MG, encontrou para a área de pasto e capoeira porcentagem de sementes germinadas de gramíneas (Poaceae) de 74\% e 50\%, respectivamente, valores próximos aos obtidos no presente estudo.

O banco de semente dos dois ambientes estudados caracterizou-se pela presença de dois grupos de plantas: ruderais graminoides (Poaceae) e não-graminoides (outras famílias). Observa-se, na figura 2, que o número médio de sementes de ruderais graminoides germinadas no banco de sementes foi de 766,38 sementes $/ \mathrm{m}^{2}$ (36,39\%) para o Ambiente I, e 1.339,51 sementes $/ \mathrm{m}^{2}$ (63,61\%) para o Ambiente II. Constata-se ainda, nessa figura, uma inversão do número de sementes germinadas entre os ambientes. No Ambiente I, que corresponde ao ambiente perturbado, registrou-se uma maior proporção de espécies pertencentes ao grupo das ruderais não-graminoides (outras famílias), enquanto que no Ambiente II (degradado) verificou-se um número elevado do grupo das ruderais graminoides e uma redução do número de sementes do grupo das ruderais não-graminoides (Figura 2). A ausência de espécies arbóreas e a presença de grande quantidade de sementes de espécies herbáceas ruderais germinadas no banco de sementes do solo registradas neste estudo pode estar relacionada com o ciclo de vida dessas espécies, a produtividade de sementes e a ausência do dossel, que, por sua vez, pode estar facilitando a dispersão de suas sementes e a incorporação no solo.

Segundo Baider et al. (1999), um fator que deve ser considerado é o histórico de uso agrícola do solo, pois áreas cultivadas mostram um banco de sementes constituído predominantemente por espécies herbáceas, comuns de áreas de cultivo. Garwood (1989) também ressalta que, em áreas agropastoris 
abandonadas, é observado o predomínio de espécies herbáceas no banco de sementes (em média 75\%), fato também verificado neste trabalho.

Tabela 1. Relação das espécies e respectivas formas de vida e número total de plântulas encontradas nas amostras do banco de sementes do solo no entorno de uma nascente na região sul de Minas Gerais. $\mathrm{RG}=$ ruderais graminoides; NRG: ruderais não-graminoides.

Table 1. Relationship total number of seedlings of the species found in samples of the seed bank of soil from one spring in the southern region of Minas Gerais. Where: RG: ruderal grass; NRG: ruderal not grass

\begin{tabular}{|c|c|c|c|c|c|}
\hline \multirow{2}{*}{ Famílias/Espécies } & \multirow{2}{*}{ Nome vulgar } & \multicolumn{2}{|c|}{ Formas de vida } & \multicolumn{2}{|c|}{ Ambientes } \\
\hline & & RG & RNG & I & II \\
\hline AMARANTHACEAE & & & & & \\
\hline $\begin{array}{l}\text { Amaranthus spinosus } \mathrm{L} \text {. } \\
\text { ASTERACEAE }\end{array}$ & caruru-de-espinho & & $\mathrm{x}$ & 4 & \\
\hline Ageratum conyzoides $\mathrm{L}$. & mentrasto & & $\mathrm{x}$ & 13 & 3 \\
\hline Emilia sonchifolia (L.) DC. & falsa-serralha & & $\mathrm{x}$ & & \\
\hline Galinsoga parviflora Cav. & picão-branco & & $\mathrm{x}$ & 33 & \\
\hline Soliva pterosperma (Juss.) Less & espinho-de-cachorro & & $\mathrm{x}$ & & \\
\hline Taraxacum officinalle Weber & dente-de-leão & & $\mathrm{x}$ & & \\
\hline CONVOLVULACEAE & & & & & \\
\hline $\begin{array}{l}\text { Ipomoea grandifolia (D.) O'Donell } \\
\text { EUPHORBIACEAE }\end{array}$ & corda-de-viola & & $\mathrm{x}$ & 1 & \\
\hline $\begin{array}{l}\text { Chamaesyce hyssopifolia (L.) Small } \\
\text { POACEAE }\end{array}$ & erva-de-andorinha & & $\mathrm{x}$ & & \\
\hline Panicum maximum & capim-tanzânia & $\mathrm{x}$ & & 132 & 259 \\
\hline MALVACEAE & & & $\mathrm{x}$ & & \\
\hline Sida sp. & vassoura & & $\mathrm{x}$ & 197 & 89 \\
\hline Total & & & & 380 & 351 \\
\hline
\end{tabular}

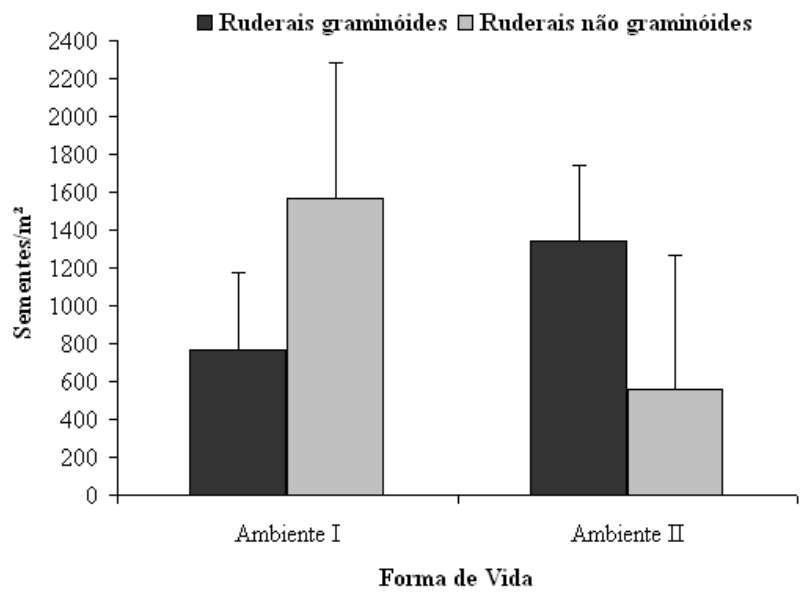

Figura 2. Número médio de sementes germinadas por $\mathrm{m}^{2}$ de espécies ruderais (Poaceae e outras) nas amostras do banco de sementes do solo em dois ambientes no entorno de uma nascente na região sul de Minas Gerais.

Figure 2. Average number of seeds germinated $\mathrm{m}^{2}$ of ruderal species (grass and not grass) on the bank of seed samples of soil from two springs in the southern region of Minas Gerais.

Neste estudo, observou-se ausência de sementes de espécies arbóreas. Porém deve-se ressaltar que os resultados obtidos podem sofrer influência da metodologia utilizada. Sabe-se que o método de 
germinação, apesar de ser o mais utilizado, devido a sua facilidade tanto na manipulação quanto no reconhecimento das sementes germinadas, apresenta-se limitado, por subestimar as amostras, devido a erros associados à dormência e mortalidade de sementes (BROWN, 1992). Portanto a amostragem para banco de sementes necessita de mais estudos, uma vez que não há consenso sobre o número de amostras e volume de solo a ser coletado. De acordo com Simpson et al. (1989), os principais problemas metodológicos no estudo do banco de sementes são: heterogeneidade dos métodos de amostragem, número insuficiente de amostras, não amostragem do solo ao longo do ano e por mais de um ano, não utilização de mecanismos de quebra de dormência, bem como fornecimento de condições ideais requeridas para germinação, além de análises estatísticas inadequadas das informações obtidas.

Alguns autores, como Young et al. (1987), estudando florestas secundárias na Costa Rica, e Sorreano (2002), estudando a dinâmica do banco de sementes em áreas de Mata Atlântica em processo de restauração, encontraram estoque bastante reduzido de espécies arbustivo-arbóreas e observaram, também, predomínio de espécies herbáceas. Siqueira (2002), estudando o banco de sementes do solo em áreas de Mata Atlântica em processo de restauração, concluiu que existe um estoque de sementes bastante reduzido com relação às espécies arbustivo-arbóreas, havendo um predomínio de espécies herbáceas invasoras, o que determina a baixa similaridade encontrada entre a flora do banco e as espécies estabelecidas no dossel.

Baider et al. (2001), em estudo realizado em quatro trechos de Mata Atlântica, com diferentes idades, constatou grande quantidade de espécies herbáceas, variando entre 56 e $67 \%$ do total de sementes de acordo com a idade considerada. Estes mesmos autores afirmam que, conforme a floresta torna-se madura, há uma redução na densidade total das sementes viáveis, bem como na densidade de sementes herbáceas, e um aumento na densidade de sementes arbustivo-arbóreas.

Siqueira (2002), monitorando áreas restauradas no estado de São Paulo, constatou, através da composição florística e da abundância de sementes presentes no banco do solo, que apenas um pequeno grupo de espécies poderá germinar, contribuindo para a regeneração da área estudada. Esse autor ainda ressalta que o número restrito de sementes é devido principalmente à baixa longevidade e ausência de dormência da maioria das espécies tropicais, que ficam pouco tempo disponível no banco.

Outro aspecto importante refere-se à sazonalidade do banco de sementes e ao fato de a amostragem ter sido realizada em maio, pois, segundo Davide et al. (1995), o período de maior dispersão das sementes das espécies arbóreas, na região, ocorre de agosto a novembro.

De acordo com Araújo et al. (2001), a forma de vida predominante em um ambiente vai depender, principalmente, do tipo de pressão sofrida, não somente na área, mas também em toda microrregião. Uhl; Clark (1983), estudando o banco de sementes em áreas onde ocorreu a degradação do ecossistema florestal para introdução de pastagens ou para cultivo, constataram que há um domínio de espécies invasoras de ervas e gramíneas (Poaceae), fato também observado neste estudo.

De acordo com Vásquez-Yanes; Orozco-Segovia (1987) e Garwood (1989), espécies herbáceas pioneiras não são componentes das florestas tropicais, mas aparecem em grande número no banco de sementes, pois, geralmente, apresentam dormência facultativa, além de possuírem eficientes mecanismos de dispersão, o que se confirma nos locais estudados, influenciados ainda pelo pequeno tamanho e grande perturbação dos fragmentos, o que facilita a dispersão dessas sementes no seu interior.

A densidade de sementes germinadas por $\mathrm{m}^{2}$ registrada neste trabalho foi de 2.332 para o Ambiente I (perturbado) e 1.896 para o Ambiente II (degradado), respectivamente (Tabela 2). Constatase, na tabela 2 , que não houve diferença significativa entre os dois ambientes em relação ao número de indivíduos germinados e à densidade de sementes, pelo teste de Scott-Knott a 5\% de probabilidade, provavelmente pela influência da alta variabilidade (alto desvio padrão) encontrada nesse tipo de estudo (amostragem).

A densidade de sementes viáveis no solo encontrada neste estudo está dentro dos padrões registrados na literatura para o banco de sementes do solo, que tem sido em torno de 25 a 1000 sementes $/ \mathrm{m}^{2}$ nas florestas tropicais primitivas. Para vegetação secundária, o número de sementes pode ser muito maior, alcançando de 3000 a 8000 sementes/m² (UHL; CLARK, 1983; GARWOOD, 1989; YOUNG, 1985; BUTLER; CHAZDON, 1998; ARAÚJO et al., 2001). A densidade de sementes encontradas nos ambientes estudados, em geral, foi maior que as densidades encontradas por outros autores: Baider et al. (1999), estudando o banco de sementes de um trecho de Floresta Atlântica Montana, encontrou uma densidade de $872 \mathrm{sem} / \mathrm{m}^{2}$; Siqueira (2002), em monitoramento de áreas restauradas no interior do estado de São Paulo, 
observou na estação seca e na chuvosa uma densidade de sementes de 245,87 e 328,53 sementes $/ \mathrm{m}^{2}$, respectivamente. Resultado semelhante ao obtido neste trabalho foi registrado por Leal Filho (1992), que encontrou, em uma área de pasto, uma densidade de 2.216 sementes $/ \mathrm{m}^{2}$.

Tabela 2. Valores dos parâmetros de densidade e diversidade nas amostras do banco de sementes do solo de dois ambientes, no entorno de uma nascente em Itumirim, Minas Gerais.

Table 2. Parameter values of density and diversity in the samples of the seed bank of soil in the two environments surrounding a spring in Itumirim, Minas Gerais.

\begin{tabular}{lcc}
\hline Parâmetros avaliados & Ambiente I & Ambiente II \\
\hline Número total de sementes germinadas & $380 \mathrm{~A}$ & $351 \mathrm{~A}$ \\
Número de sementes germinadas por $\mathrm{m}^{2}$ & $2.332 \mathrm{~A}$ & $1.896 \mathrm{~A}$ \\
Número de sementes germinadas por amostra (média \pm desvio padrão) & $42,22 \pm 30$ & $39 \pm 29$ \\
Número de indivíduos & 380 & 351 \\
Número de espécies registradas & 6 & 3 \\
Índice de diversidade de Shannon (H') & $1,099 \mathrm{a}$ & $0,613 \mathrm{~b}$ \\
Índice de equabilidade de Pielou (J') & 0,613 & 0,555 \\
\hline
\end{tabular}

Verifica-se, na tabela 2, que o valor do índice de diversidade de Shannon-Wiener para o Ambiente I (H' 1,099) foi significativamente superior ao encontrado no Ambiente II $\left(H^{\prime} 0,613\right), P<0,001$. Quando se analisam os dados de diversidade obtidos no Ambiente I (perturbado), constata-se que esses valores estão próximos daqueles encontrados por Araújo et al. (2001) em um estudo do banco de sementes do solo em um fragmento de floresta secundária com 30 anos de idade em área de Floresta Amazônica no estado Pará.

O desenvolvimento das plântulas foi observado durante um período de 210 dias consecutivos. Verifica-se, neste trabalho, que a maior proporção de sementes germinadas, nos dois ambientes, ocorreu nos primeiros 30 dias de observação, quando constatou-se, aproximadamente, $77 \%$ de emergência no Ambiente I e 61\% no Ambiente II (Figura 3).

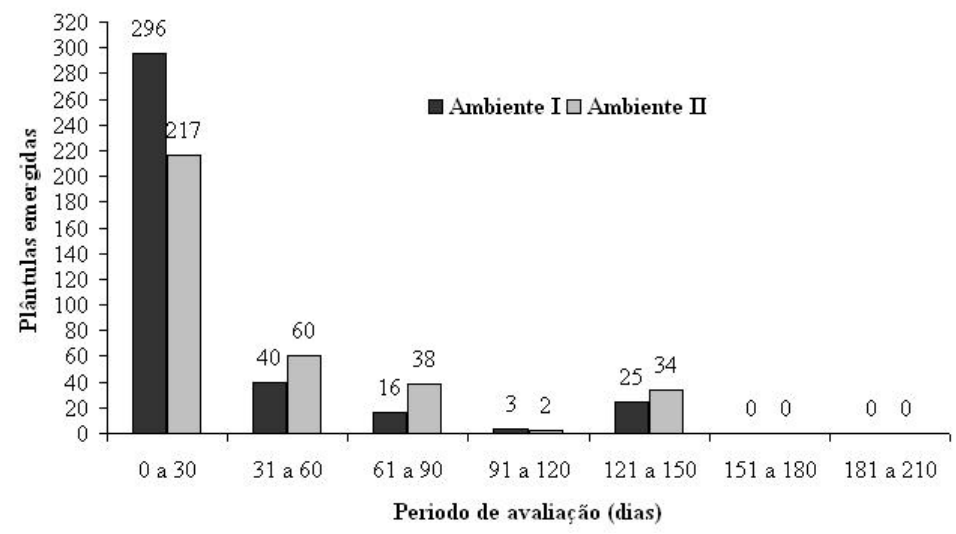

Figura 3. Número de plântulas emergidas de espécies ruderais nas amostras do banco de sementes do solo em dois ambientes no entorno de uma nascente em Itumirim, Minas Gerais, no período de 210 dias de avaliação.

Figure 3. Number of seedlings emerged from ruderal species in the samples of the seed bank of soil in two environments of a spring in Itumirim, Minas Gerais, during the 210 days of evaluation.

Entre trabalhos que obtiveram resposta semelhante está o de Siqueira (2002), que verificou rápida resposta de germinação nos primeiros meses de estudo, e o de Araújo et al. (2001), relatando que $40 \%$ dos bancos de sementes do solo das florestas sucessionais estudadas emergiram no primeiro mês de avaliação.

Esse resultado era esperado, já que grande parte das sementes formadoras do banco é fotoblástica positiva e, por isso, são estimuladas pelo aumento na intensidade de luz. Com a homogeneização das 
amostras, as sementes que poderiam estar nas camadas mais profundas passaram a receber luz, estimulando assim sua geminação.

Deve-se mencionar ainda que a regeneração natural de espécies arbóreas em áreas abertas parece ser mais dependente da disseminação de sementes que iniciam a germinação logo após a disseminação do que propriamente do banco de sementes, uma vez que a germinação da maioria das espécies pioneiras é estimulada pela presença de luz, e na área de pasto, assim que a semente chega, ela já tem condições de iniciar o processo de germinação.

\section{CONCLUSÕES}

Com base na hipótese testada neste trabalho, pode-se concluir que:

- a composição e a densidades de sementes variou de acordo com o grau de degradação dos ambientes avaliados;

- o potencial de uso do banco de sementes do solo como mecanismo na recuperação das nascentes decresceu com o aumento do nível de degradação;

- o estabelecimento da vegetação arbórea no entorno da nascente avaliada não pode estar baseada apenas na regeneração natural, necessitando de intervenções humanas.

\section{REFERÊNCIAS}

APG II - Angiosperm Phylogeny Group. An update of the Angiosperm Phylogeny Group classification for the orders and families of flowering plants: APG II. Botanical Journal of the Linnean Society, London, v. 141, n. 4, p. 399-436, apr. 2003.

ARAÚJO, M. M.; OLIVEIRA, F. de A.; VIEIRA, I. C. G.; BARROS, P. L. C. de.; LIMA, C. A. T. de. Densidade e composição florística do banco de sementes do solo de florestas sucessionais na região do Baixo Rio Guamá, Amazônia Oriental. Scientia Forestalis. Piracicaba. v, n. 59, p. 115-130, 2001.

BAIDER, C.; TABARELLI, M.; MANTOVANI, W. The soil seed bank during atlantic forest regeneration in southeast Brazil. Revista Brasileira de Biologia, Rio de Janeiro, v. 61, n. 1, p. 35-44, 2001.

O banco de sementes de um trecho de Floresta Atlântica Montana (São Paulo, Brasil). Revista Brasileira de Biologia, Rio de Janeiro, v. 59, n. 2, p. 319-328, 1999.

BRASIL. Ministério da Agricultura e Reforma Agrária. Normais climatológicas 1961-1990. Brasília: MARA, $1992.84 \mathrm{p}$.

BROWER, J. E.; ZAR, J. H. Field and laboratory methods for general ecology. Dubuque: W. M. C. Brown, 1984. $84 \mathrm{p}$.

BROWN, D. Estimating the composition of a forest seed bank: a comparison of the seed extraction and seedling emergence methods. Canadian Journal of Botany, v. 70, n. 8, p. 1603-1612, 1992.

BUTLER, B. J.; CHAZDON, R. L. Species richness, spatial variation and abundance of soil seed bank of a secondary tropical rain forest. Biotropica, v. 30, n. 2, p. 214-222, 1998.

DAVIDE, A. C.; FARIA, J. M.; BOTELHO, S. A. Propagação de espécies florestais. Belo Horizonte: CEMIG/UFLA, 1995, 45 p.

GARWOOD, N. C. Tropical soil seed banks: a review. In: LECK, M. A.; PARKER, V. T.; SIMPSON, R. L. Ecology of soil seed banks. 1989.

GRIME, J. P. Seed banks in ecological perspective. In: LECK, M. A.; PARKER, V. T.; SIMPSON, R. L. Ecology of soil seed banks. 1989.

HALL, J. B.; SWAINE, M. D. 1980. Seed Stocks in Ghanaian Forest Soils. Biotropica, 12: 256-263.

HARPER, J. L. Population biology of plants. New York: Academic Press, 1977. 892 p. 
HOPKINS, M. S.; GRAHAM, A. W. Viable soil seed banks in disturbed lowland tropical rainforests in North Queensland, Australia, Melboure. Australy Journal Ecology, v. 9, p. 71-79, 1984.

KAGEYAMA, P. Y.; VIANA, V. M. Tecnologia de sementes e grupos ecológicos de espécies arbóreas tropicais. In: Simpósio Brasileiro de Tecnologia de Sementes Florestais. 1991: Atibaia. Anais... Atibaia, 1991. p. 197-215.

KREBS, C. J. Ecological methodology. New York: Harper and Row, 1989.

LEAL FILHO, N. Caracterização do banco de sementes de três estádios de uma sucessão vegetal na Zona da Mata de Minas Gerais. 1992. 116 p. Dissertação (Mestrado em Ciência Florestal) Universidade Federal de Viçosa, MG.

MARTINS, S. V. Recuperação de matas ciliares. Viçosa: Aprenda Fácil, 2001. 146 p. il.

NEPSTAD, D. C.; UHL, C.; PEREIRA, C. A.; SILVA, J. M. C. Estudo comparativo do estabelecimento de árvores em pastos abandonados e florestas adultas da Amazônia Oriental. Gascon, C. \& Moutinho, P. (eds.). Floresta Amazônica: dinâmica, regeneração e manejo. Manaus, INPA. 1998. p. 191-218.

ONAINDIA, M.; AMEZAGA, I. Seazonal variation in the seed banks of native woodland and coniferous plantations in northern Sapin. Forest Ecology and management, Amsterdam, v. 126, n. 2, p. 163-172, 2000.

PUTZ, F. E.; APPANAH, S. Buried seeds, newly dispersed seeds, and dynamics of a lowland forest in Malaysia. Biotropica, n. 19, p. 326-333, 1987.

RICHARDS, P. W. 1998. The tropical rain forest: an ecological study. Cambridge: Cambridge University Press, p. 115-116.

ROBERTS, H. A. 1981. Seed banks in the soil. Advances in Applied Biology, Cambridge Academic Press, v. 6, 55 p.

ROIZMAN, L. G. Fitossociologia e dinâmica do banco de sementes de populações arbóreas de floresta secundária em São Paulo. 1993. 184 p. Dissertação (Mestrado em Ecologia) - Instituto de Biociências, São Paulo.

SAULEI, S. M.; SWAINE, M. D. Rain forest seed dynamics during succession at Gogol, Papua-Nova Guine. Journal of Ecology, Oxford, v. 62, n. 4, p. 1133-1152, 1988.

SIMPSON, R. L.; LECK, M. A.; PARKER, V. T. Seed banks: general concepts and methodological issues. In: LECK, M. A.; PARKER, V. T.; SIMPSON, R. L. Ecology of soil seed banks. 1989.

SIQUEIRA, L. P. de. Monitoramento de áreas restauradas no interior do Estado de São Paulo, Brasil. 2002. 116 p. Dissertação (Mestrado em Conservação e Ecossistemas Florestais) - Escola Superior de Agricultura Luiz de Queiroz, Piracicaba.

SMITH, A. P. Respuestas de hierbas del sotobosque tropical a claros ocasionados por la caída de árboles. Revista de Biologia Tropical, San José, v. 35, p. 111-118, 1987.

SORREANO, M. C. M. Avaliação de aspectos da dinâmica de florestas restauradas, com diferentes idades. 2002. 145 p. Dissertação (Mestrado em Engenharia Florestal) - Escola Superior de Agricultura Luiz de Queiroz, Piracicaba.

SOUZA, S. C. P. M. de. Análise de alguns aspectos de dinâmica florestal em uma área degradada no interior do Parque Estadual do Jurupará, Ibiúna, São Paulo. 2002. 84 p. Dissertação (Mestrado em Engenharia Florestal) - Escola Superior de Agricultura Luiz de Queiroz, Piracicaba.

TEKLE, K.; BEKELE, T. The role of soil seed banks in the rehabilitation of degraded hillslopes in Southern Wello, Ethiopia. Biotropica, p. 32, n. 1, p. 23-32, 2000.

UHL, C.; BUSCHBACHER, R.; SERRÃO, E. A. S. Abandoned pastures in Eastern Amazonia: 1-patterns of plants succession. Journal of Ecology, v. 76, p. 663-681, 1988. 
UHL, C.; CLARK, H. Seed ecology of selected amazon basin sucessional species. Botanical Gazette, v. 144, p. 419-425, 1983.

VÁSQUEZ-YANES, C.; OROZCO-SEGOVIA, A. Fisiologia ecológica de semillas en la Estacion de Biologia Tropical "Los Tuxtlas", Veracruz, México. Revista de Biologia Tropical, San José, v. 35, p. 85-89, 1987.

VIANA, V. M. 1990. Seed and seedling availability as a basis for management of natural forest regeneration. p. 99-115. In: ANDERSON, A. B. Alternatives to deforestation: steps toward sustainable use of the Amazon Rain Forest. New York, Columbia University Press.

WHITMORE, T. C. An introduction to tropical rain forests. Blackwell, London. 1990.

WIESENMÜLLER, J.; DENICH, M.; VLECK, P. L. G. Regeneração vegetativa de capoeira na região da Amazônia Oriental, Brasil. p. 101-105. In: KANASHIRO, A. B.; PARROTA, J. A. (Eds.). Manejo e reabilitação de áreas degradadas e florestas secundárias na Amazônia. Belém: Embrapa, 1995.

YOUNG, K. R. Deeply buried seeds in a tropical wet forest in Costa Rica. Biotropica. v. 17, n. 4. p. 336$338,1985$.

YOUNG, K. R.; EWEL, J. J.; BROWN, B. J. Seed dynamics during forest succession in Costa Rica. Vegetatio, v. 71, p. 157-173, 1987.

ZAR, J. H. Bioestatiscal analysis. New Jersey, Prentice-Hall. 1996. 